\title{
Correlations of Animal Welfare Scores with First Lactation Milk Yield of Dual Purpose Cows
}

\author{
Cigdem Durmaz ${ }^{1, a}$, Savas Atasever ${ }^{1, b, *}$ \\ ${ }^{l}$ Department of Animal Science, Faculty of Agriculture, University of Ondokuz Mayls, 55139 Atakum/Samsun, Turkey \\ *Corresponding author

\begin{tabular}{|c|c|}
\hline A R T I C L E I N F O & A B S T R A C T \\
\hline $\begin{array}{l}\text { Keywords: } \\
\text { Animal needs index } \\
\text { Animal welfare } \\
\text { Cattle }\end{array}$ & $\begin{array}{l}\text { The objective of this study was to determine the relationships between animal welfare scores (AWS) } \\
\text { and milk production in dairy cattle. AWS traits on locomotion ability (LA), social interaction (SI), } \\
\text { flooring (F), indoor conditions (IC) and stockmanship effect (SE) were scored by a } 100 \text { points scale } \\
\text { in a total of } 51 \text { farms in Samsun region of Turkey. First lactation milk yield (FLMY) records of } \\
\text { Brown Swiss and Simmental cows were used as milk production trait. All components were assessed } \\
\text { by } t \text {-test to determine the effects of the welfare traits on FLMY. The overall mean of AWS was } \\
\text { calculated to be } 74.05 \pm 1.69 \text {, and therefore the farms were founded within a "suitable" class. It was } \\
\text { estimated moderate correlations among the parameters except for AWS and SI, however, no } \\
\text { statistically significant difference was estimated between AWS and FLMY of the cows. SE was } \\
\text { revealed the most important factor on AWS of the farms. Finally, routine scoring cattle farms to } \\
\text { decide their suitability for animal needs is advised to herd owners for managing rentable populations } \\
\text { in the farms. }\end{array}$ \\
\hline
\end{tabular}

Cattle

Herd management

Milk production

\section{Introduction}

The main purpose of animal science is obtaining elite herds with high genetic merit. At this point, optimizing environmental conditions affecting productivity should not be regarded as one of the crucial topics, although it is essential in itself. In other words, in addition to focus on genetic traits, adjusting non-genetic factors exposed to livestock plays equal importance in boosting the profitability. Feeding, temperature, husbandry practices, flooring, hygiene or milking management may cause adverse effect on the performance of an animal. Therefore, field studies carried out to determine the potential effects of non-genetic factors are still needed.

Today, animal welfare has gained popularity in many countries to obtain more elite herds. Barning, feeding, health and behavior are attractive points composing welfare term. According to an initial study (Goncu et al., 2016), cows exposed to stress had lower levels by milk yield, beef quality and welfare. Moreover, these inverse cases may be the main reasons for less income in the farm economy. For dairy cows, criterions on herd requirements those based on barns were designed by Bartussek (2001) as Animal Needs Index (ANI). Suitability levels of barns for welfare can be determined using this index and required management measures can be taken according to this scheme. At the end of the scoring, means for ANI and its subcomponents on locomotion, social behaviors and hierarchy, flooring materials, suitability of indoor status and herd keeper (stockman) may be assessed to be substantial markers. Reports emphasized that limited area per cow in crowded herds caused inverse effect on both animal behavior and hierarchy. Besides, unkind treatments during the milking process may provoke fair and less milk production (Rushen et al., 1999). Haskell et al. (2006) indicated that cows kept indoor throughout a year being subjected to leg or foot problems and poor welfare and productivity. Also, tie stall barns allow only resting and lying, but prevent strolling (Ravagnolo et al., 2000). In addition to mentioned factors, a close association of stockman with production and animal welfare has been declared (Kauppinen, 2010). 
As parallel to many countries, interest on animal welfare has shown an elevated trend in Turkey. Although many studies have been carried out to determine the effects of non-genetic components on milk production of cows (Koc 2008; Atasever and Stadnik, 2015; Kul et al., 2019), those have mostly focused only Holstein breed, behavior and stockman effects have not been extensively studied yet. Whereas, revealing the welfare potential of barns established by high finances and investigating the correlations of these levels with milk production may be seen as a basic principle to boost productivity in cattle herds.

The aim of this study was to determine the relationships between animal welfare scores (AWS) and milk yield in Simmental and Brown Swiss cows.

\section{Materials and Methods}

Milk production records of milking cows of a total of 51 farms enrolled to Dairy Breeders Association (DBA) of Samsun city located in the Black Sea region of Turkey farms were used to be study materials. The mean of cows kept in the total of 158 farms of DBA was calculated as 7.23 per farm and thus, 51 farms those had $\geq 8$ cows were chosen to examine by AWS between September and December 2017. All farms had similar feeding and herd management conditions during the investigation period. To evaluate milk production levels, first lactation milk yield (FLMY) records of Simmental (S) and Brown Swiss (BS) cows were noted. To examine AWS levels, animal needs index (ANI) scale designed by Bartussek (2001) was modified using 100 points for each trait. Locomotion ability (LA), social interaction (SI), flooring (F), indoor conditions (IC) and stockmanship effect (SE) were constituted as AWS components. The indices of AWS components were scored directly by the same assessor on the animals, barns or pasture by visually or interviews with the farm owners. For this aim, items were scored at the same hours after morning milking process. AWS assessment was completed within 30-45 min for each farm. While LA, SI and SE means were calculated from five indices, F and IC means were obtained using four parameters. Indices of the AWS components were constituted as follows:

- $\quad$ LA: keeping area, number of cows lying down, stall type, outdoor/pasture areas,

- SI: keeping area, total cow number, hierarchy /grouping, outdoor/pasture areas,

- $\quad F$ : softness of floor, cleanliness of lying/locomotion /activity/pasture areas,

- IC: light, air quality, dryness of floor, noise,

- $S E$ : cleanliness of the cows/equipment/barns, hooves condition, hygiene of stockman.

Five AWS components were evaluated according to their means (1-25: poor, 26-50: moderate, 51-75: suitable and $\geq 76$ : excellent). To determine the effects of the welfare traits on FLMY, all components were divided to two groups and analyzed by t-test. Also, correlation coefficients among all parameters were estimated by Kendall's tau-b method. All statistical procedures were performed using SPPS.17 packet program.

\section{Results and Discussion}

In this study, descriptive values of AWS components are given in Table 1. Calculated general AWS of this study (74.05 \pm 1.69$)$ points out that investigated farms might be inserted in a suitable class. This result was parallel to the findings of Popescu et al. (2009) and Furnaris et al. (2016), and also, more practicable than the findings of Seo et al. (2007).

As seen, the highest and the lowest means were calculated from SI and IC, respectively. Really, difference up to 32 points might be attractive between two traits. However, clear differences of SI with the other traits revealed a marked role of this parameter on the general AWS. It can be assumed that SI was a factor based on animals; on the other hand, other traits were highly derived from barns or human. In this context, revisions on barn facilities and herd management programs can be offered to herd owners to boost animal welfare level in the examined farms.

Table 2 indicates that there was no significant difference in FLMY between subgroups of AWS components allocated by their mean scores. Hristov et al. (2014) and Kara et al. (2015) reported that cows kept in barns with restricted by locomotion had lower milk yield. In this study, cows had kept in barns with higher LA scores produced $2.84 \%$ more milk when compared to lower ones, but no statistical difference was observed between two groups. However, stall dimensions were observed as fairly insufficient in the farms and this case might be restricted the duration of lying behavior. At this point, allowing more locomotion facilities to milking cows can be proposed to boost milk production in dairy farms.

The calculated mean score for SI $(93.50 \pm 0.86)$ was interesting in Table 2. The farms might be evaluated into excellent class according to this level. Simensen et al. (2010) emphasized that milk production of cows elevated when herd size increased. As parallel to this information, it could be expected more milk yield from farms with higher SI, but no significant difference was determined in FLMY between two subgroups. This result might be explained by a narrow variation in FMLY levels of dual purpose cows those examined here.

Although no statistically difference was obtained between two subgroups $(\mathrm{P}=0.684)$, farms with higher $\mathrm{F}$ scores had more milk up to $126 \mathrm{~kg}$ compared to the others (Table 2). As a general statement, the farms evaluated here might be presumed within the acceptable threshold by $\mathrm{F}$ scores. However, using sand or soft materials instead of concrete floor are advised to herd owners those had lower $\mathrm{F}$ scores to prevent foot disorders and to boost welfare status of the animals.

FLMY values of IC was found to be similar in the present study (Table 2). While Furnaris et al. (2016) indicated the relationships of light and hygiene with milk production, De Vries et al. (2015) emphasized to the correlation between lighting of the barns and animal welfare. Also, Peli et al. (2016) point out to air quality in barns. At this point, taking additional measures on IC could be seen to be a beneficial approach to elevate income level of the farms. 
Table 1 Descriptive values of AWS components

\begin{tabular}{l|cccc}
\hline \multicolumn{1}{c|}{ Trait } & $\mathrm{n}$ & Min & Max & Score $(\overline{\mathrm{X}} \pm \mathrm{S})$ \\
\hline LA & 51 & 44.00 & 80.00 & $70.49 \pm 1.29$ \\
SI & 51 & 70.00 & 100.00 & $93.50 \pm 0.86$ \\
F & 51 & 36.00 & 100.00 & $70.39 \pm 2.13$ \\
IC & 51 & 30.00 & 90.00 & $61.66 \pm 2.51$ \\
SE & 51 & 36.00 & 100.00 & $74.27 \pm 2.65$ \\
General & 51 & 48.70 & 91.20 & $74.05 \pm 1.69$ \\
\hline
\end{tabular}

LA: Locomotion ability, SI: social interaction, F: flooring, IC: indoor conditions, SE: stockmanship effect

Table 2 Milk production by evaluated trait scores

\begin{tabular}{ll|cc}
\hline \multicolumn{1}{c}{ Trait } & Score & $\mathrm{n}$ & FLMY $(\overline{\mathrm{X}} \pm \mathrm{S})$ \\
\hline \multirow{2}{*}{ LA } & $\leq 70 \mathrm{p}$ & 25 & $3199.920 \pm 276.528$ \\
& $\geq 71 \mathrm{p}$ & 26 & $3290.980 \pm 142.752$ \\
\hline \multirow{2}{*}{ SI } & $\leq 93 \mathrm{p}$ & 16 & $3167.687 \pm 201.782$ \\
& $\geq 94 \mathrm{p}$ & 35 & $3282.300 \pm 203.573$ \\
\hline \multirow{2}{*}{$\mathrm{F}$} & $\leq 70 \mathrm{p}$ & 26 & $3308.076 \pm 260.056$ \\
& $\geq 71 \mathrm{p}$ & 25 & $3182.140 \pm 158.487$ \\
\hline \multirow{2}{*}{ IC } & $\leq 61 \mathrm{p}$ & 25 & $3249.000 \pm 277.678$ \\
& $\geq 62 \mathrm{p}$ & 26 & $3243.788 \pm 141.251$ \\
\multirow{2}{*}{ SE } & $\leq 74 \mathrm{p}$ & 22 & $3328.318 \pm 313.306$ \\
& $\geq 75 \mathrm{p}$ & 29 & $3184.155 \pm 129.520$ \\
\hline \multirow{2}{*}{ General } & & 51 & $3246.343 \pm 152.408$ \\
\hline
\end{tabular}

LA: Locomotion ability, SI: social interaction, F: flooring, IC: indoor conditions, SE: stockmanship effect

Table 3 Kendall's tau-b correlation coefficients of evaluated traits

\begin{tabular}{l|cccccc}
\hline & SI & F & IC & SE & AWS & FLMY \\
\hline LA & 0.395 & 0.598 & 0.596 & 0.617 & 0.721 & 0.189 \\
SI & & 0.318 & 0.347 & 0.343 & 0.410 & 0.084 \\
F & & & 0.578 & 0.691 & 0.745 & 0.034 \\
IC & & & & 0.735 & 0.786 & 0.080 \\
SE & & & & & 0.849 & -0.002 \\
Genel & & & & & & 0.055 \\
\hline
\end{tabular}

LA: Locomotion ability, SI: social interaction, F: flooring, IC: indoor conditions, SE: stockmanship effect, AWS: animal welfare score, FLMY: first lactation milk yield

In this study, effect of SE on FLMY was not significant (Table 2). Mattiello et al. (2009) emphasized that stockman is principally responsible for solving indoor problems related to animal welfare. Really, it might be expected that hygiene and sanitary applications have been ensured by herd stockman in cattle farms. However, calculated similar means by SE groups in this study might be caused by narrow variations in FLMY of S and BS cows reared in the evaluated farms. In other words, it might be observed statistical differences between the groups of AWS components when examined the higher number of farms. In the view of the general mean of AWS, FLMY of the cows were also compared (Figure 1). As expected, no significant difference was determined between two subgroups here. However, elevating both the means of AWS and its components and boosting milk yield of the cows have been detected as the critical points according to obtained consequences.

Correlations of all traits evaluated in this study are seen in Table 3. Except for SI, all components moderate correlated with AWS. This case was not found as in agreement with the findings of Ofner et al. (2003) who determined marked associations between behavior and ANI. Also, relatively high correlation coefficient was estimated between SE and AWS. Interestingly, calculated correlations of the parameters with FLMY were weak.
Obtained findings here were found to be contrast with the results of Soltysiak and Nogalski (2010) who emphasized that cows within the higher social order in the herds had more milk production. Besides, Kara et al. (2015) informed that cows with advantage by locomotion had higher milk yield in cattle herds. The different results between this study and the other might strongly be caused by the difference of cow breeds and their milk production levels evaluated in the studies. Finally, it was noticed that the most important trait effecting AWS was SE ( $r=0.849)$ in the view of the estimated correlations here.

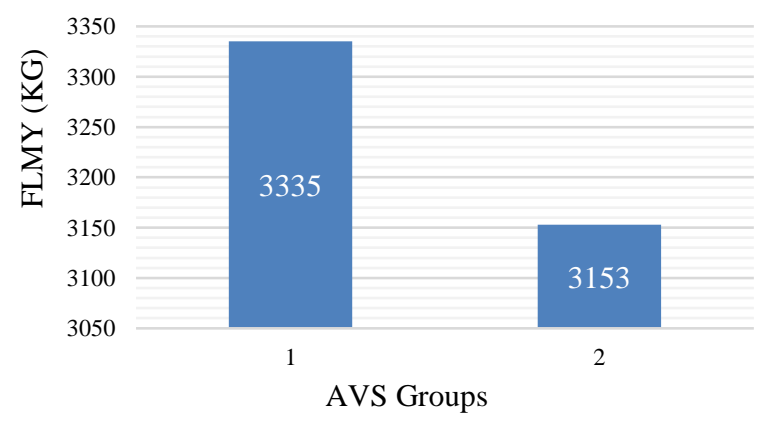

Figure1 Change of FLMY by AWS groups

(FLMY: first lactation milk yield; AWS: animal welfare scores; $1=\leq 74 \mathrm{p} ; 2=>74 \mathrm{p})$ 


\section{Conclusion}

According to study results related correlations of AWS with first lactation milk yield of dual purpose of Brown Swiss and Simmental cows, evaluated farms might be classified within suitable class. While no significant effect of AWS components on milk production was determined, stockman was revealed the most important factor on the general AWS of the evaluated farms. This finding might be found to be remarkable due to exposing human factor on the relations of animals with barns.

In conclusion, routine scoring cattle farms to decide their suitability for animal needs is advised to herd owners for managing rentable populations in their farms.

\section{References}

Atasever S, Stadnik L. 2015. Factors affecting daily milk yield, fat and protein percentage, and somatic cell count in primiparous Holstein cows. Indian J. Anim. Res., 49:313316.

Bartussek H. 2001. An Historical Account of the Development of the Animal Needs Index ANI-35L as Part of the Attempt to Promote and Regulate Farm Animal Welfare in Austria: An Example of the Interaction Between Animal Welfare Science and Society, Acta Agric. Scand. A Anim. Sci., 51: 34-41.

De Vries M, Bokkers EAM, Van Reenen CG, Engel B, Van Schaik G, Dijkstra T, De Baer IJM. 2015. Housing and Management factors associated with indicators of dairy cattle welfare. Prev. Vet. Med., 118: 80- 92.

Furnaris F, Ghımpeteanu O, Predoi G. 2016. Dairy Cows Welfare Assessment in a Farm from South Eastern Romania. Agriculture an Agricultural Science Procedia, 10: 403- 407.

Goncu S, Koluman N, Serbester U, Gorgulu M. 2016. Animal Welfare Issues and Critical Control Points in Dairy Cattle Farming. Cukurova J. Agric. Food Sci., 31: 9-20.

Haskell MJ, Rennie LJ, Bowell VA, Bell MJ, Lawrence AB. 2006. Housing system, milk production, and zero-grazing effects on lameness and leg injury in dairy cows. J. Dairy Sci., 89: 4259-4266.

Hristov S, Zlatanovic Z, Stankovic B, Dokmanovic M, Andric D, Mekic C. 2014. The relationship between rearing system, animal needs index and dairy cows milk traits. Mljekarstvo, 64: 186- 194
Kara N, Galic A, Koyuncu M. 2015. Comparison of Milk Yield and Animal Health in Turkish Farms with Differing Stall Types and Resting Surfaces. Asian Australas. J. Anim. Sci., 28: 268-272.

Kauppinen T, Vainio A, Valros A, Rita H, Vesala KM. 2010. Improving animal welfare: qualitative and quantitative methodology in the study of farmers' attitudes. Anim. Welf., 19: 523-536.

Koc A. 2008. A study of somatic cell counts in the milk of Holstein-Friesian cows managed in Mediterranean climatic conditions. Turk. J. Vet. Anim. Sci., 32 (1): 13-18.

Kul E., Sahin A., Atasever S., Ugurlutepe E., Soydaner M. 2019. The effects of somatic cell count on milk yield and milk composition in Holstein cows. Vet. Arhiv., 89 (2): 143-154.

Mattiello S, Klatz C, Borali D, Minera M, Ferrante V, Conali E. 2009. Welfare problems in alpine dairy cattle farms in Alta Adige. Ital. J. Anim. Sci., 8: 628- 630.

Ofner E, Amon T, Lins M, Amon B. 2003. Correlations between the results of animal welfare assessments by the TGI $35 \mathrm{~L}$ Austrian Animal Needs Index and health and behavioural parameters of cattle. Anim. Welf., 12: 571-578.

Peli A, Pietra M, Giacometti F, Mazzi A, Scacco G, Serraino A, Scagliarini L. 2016. Survey an animal welfare in nine hundred and forty three Italian dairy farms. Ital. J. Food Saf., 5 (5832):50-56.

Popescu S, Borda C, Lazar EA, Hegedus CI. 2009. Assessment of dairy cow welfare in farms from Transylvania, 44th Croatian \& 4th International Symposium on Agriculture, 1620 February, Opatija, Croatia.

Ravagnolo O, Misztal I, Hoogenboom G. 2000. Genetic component of heat stress in dairy cattle, development of heat index function. J. Dairy Sci., 83:2120-2125.

Rushen J, De Passille AM, Munkgaard L. 1999. Fear of people by cows and effects on milk yield, behavior, and heart rate at milking. J. Dairy Sci., 82:720-727.

Seo T, Date K, Daigo, T, Kashiwamura F, Sato, S. 2007. Welfare assessment on japanese dairy farms using the Animal Needs Index. Anim. Welf., 16: 221- 223

Simensen E, Østeras O, Bøe KE, Kielland C, Ruud LE, Næss G. 2010. Housing system and herd size interactions in Norwegian dairy herds; association with performance and disease incidence. Acta Scand., 52:14.

Soltysiak T, Nodalski Z. 2010. The effects of social hierarchy in a dairy cattle herd on milk yield. Pol. J. Nat. Sci., 25: 22-30. 